\title{
Practical applications of fuzzy set theory in flight safety management
}

\author{
Valeriy Sharov ${ }^{1 *}$, Pavel Polyakov ${ }^{1}$ and Sergei Tolstykh ${ }^{1}$ \\ ${ }^{1}$ Moscow State Technical University of Civil Aviation, 20 Kronshtadtsky blvd, Moscow, 125993, \\ Russia.
}

\begin{abstract}
Risk management is a core of Safety Management System (SMS) of airline. It works in high level of uncertainty and is dealing with variety of information which is fuzzy in nature. So the fuzzy set theory (FST) is natural instrument that should be applied for solving problems that SMS faced with. The article provides a brief overview of examples of the use of FST elements in safety risk management, presents the results of processing expert surveys using fuzzy methods, and describes the developed practical method for assessing the index of probability of an aviation event based on the fuzzy inference technology.
\end{abstract}

\section{Introduction}

In the modern sense, flight safety is a state of acceptable risk, so risk management is a core of safety management system (SMS). The presence of SMS in airlines is mandatory according to the documents of the Russian Federation [1] and ICAO [2]. The most common method of safety risk management is a "matrix of consequences and probabilities", recommended by ICAO [3]. This is a qualitative method that corresponds to the "technocratic concept of risk" [4]. Risk is assessed as a combination of expert assessments of the probability and severity of a possible event on 5-point ordinal scales: for probability from 1 to 5, and for severity - from A to E. The final matrix divides all assessments into three groups, and the risks are prioritized accordingly.

The method has limitations [5,6]. It can't be used for quantitative and statistical calculation But in the practice of airlines, it is not uncommon to try to "circumvent" the restrictions by entering numerical coefficients into the matrix. Indeed, if one can obtain estimates of the probability $P^{*}$ and severity $S^{*}$ of the predicted event in conventional units, then the risk can be estimated as:

$$
R^{*}=P^{*} S^{*}
$$

There are known options for "linking" the $\mathrm{P}^{*}$ indicator to the probabilities or frequencies of events that are published in corporate as well as in government documents [7]. An example from the document of UK Civil Aviation Authority is given in Table 1.

\footnotetext{
* Corresponding author: v.sharov@mstuca.aero
} 
Table 1. Recommendations for evaluating the "probability indicator" in CAP-712 [8]

\begin{tabular}{|c|c|c|c|}
\hline \multicolumn{2}{|c|}{} & $\begin{array}{c}1 \text { to } 10^{-5} \text { per } \\
\text { flight hour }\end{array}$ & May occur once or several times during operational life \\
\hline 4 & Probable & $\begin{array}{c}10^{-5} \text { to } 10^{-7} \\
\text { per flight hour }\end{array}$ & $\begin{array}{c}\text { Unlikely to occur during total operational life of each system } \\
\text { but may occur several times when considering several systems } \\
\text { of the same type }\end{array}$ \\
\hline 2 & $\begin{array}{c}\text { Extremely } \\
\text { Remote }\end{array}$ & $\begin{array}{c}10^{-7} \text { to } 10^{-9} \\
\text { per flight hour } \\
<10^{-9} \text { per } \\
\text { flight hour }\end{array}$ & $\begin{array}{c}\text { Unlikely to occur when considering systems of the same type, } \\
\text { but nevertheless, has to be considered as being possible }\end{array}$ \\
\hline 1 & $\begin{array}{c}\text { Extremely } \\
\text { Improbable }\end{array}$ & Should virtually never occur in the whole fleet life \\
\hline
\end{tabular}

The wording and recommendations for estimating the indicator vary from document to document. There can be no clear instructions, because terms like "often" or "sometimes" for events in operation have different meanings for different experts and for different airlines.

In addition, these estimates are applicable to rare events such as an accident, and the airline performs risk assessments for less significant events like incidents and so-called harbingers. Obviously, any such estimates are fuzzy in nature.

To take into account the fuzziness, the blurring of estimates, these "shades of gray" in order to build "the better models of reality" and use "the ability to exploit the tolerance for imprecision " [9] allows the fuzzy sets theory (FST).

This article provides a solution to the problem of developing $\mathrm{P}^{*}$ indicator for an airline in conventional units based on a fuzzy logical inference and provides a brief analysis of the use of FST for flight safety management.

\section{Some examples of the use of FST for safety management}

FST based models are built for the risk of various events. Fuzzy Logic attempts to model our sense of words, our decision making and our common sense. As a result, it is leading to new, more human, intelligent systems [11].

Effective joint use of FST and other methods. For example, in [10] the synthesis of the FST and the Systems Theoretic Accident Model and Process (STAMP), Functional Resonance Analysis Method (FRAM) and Resilience Analysis Grid (RAG) is discussed. The methods of qualitative analysis (FRAM and STAMP) are descriptive, and fuzzy logic makes it easier to quantify and account for variability. However, despite the advantages, the model will still be limited. Developers are forced to minimize the number of input variables to avoid the "rule explosion" problem, as they called it. A large amount of input data leads to a sharp increase in the size of the rule base.

There are not many examples of practical application of FST in the field of flight safety. Conditionally, this direction can include CFIT - program for assessing the risk of a "controlled flight into terrain", the FORAS - flight operations risk assessment system [12], and FRAT - flight risk assessment tool. These programs are designed for expert assessment of the risk of a particular flight directly in points of a certain scale.

In [13] and some other works, the idea of using FST is expressed in the most general form, with reference to the "ICAO matrix" and similar matrices of other organizations. Of the recent works on flight safety, which actually use the methods of FST, it is appropriate to note the articles related to the current topic of the safety of unmanned aircraft systems (UAS). The article [14] presents a method that solves the problem of monitoring the state of power supply. The method allows you to use fuzzy logic based on the current voltage, battery temperature, wind parameters to determine the remaining battery life and 
automatically adjust the flight plan. But the claim that no external pilot intervention will be required is controversial.

In [15] fuzzy logic solutions are recommended for integrating UAS into US airspace. The development of fuzzy rules for motion modeling will be carried out by experts. It is planned to conduct testing with the inclusion of emergency situations. A fuzzy logic algorithm has been developed that will use data from the automatic dependent system broadcast (ADS-B). The algorithm provides solutions to conflict situations in the air. This approach is certainly promising in the context of the growing number of UAS in the world.

Among the implemented developments, we note the study [16], which examines in detail the issues of the use of FST in SMS in the aircraft maintenance organization "S7ENGINEERING". A general fuzzy mathematical model of decision-making in risk management was formed.

In the article [17], it is proposed to use FST in conjunction with FMECA. As is well known, this method involves risk assessment based on the priority risk number - RPN:

$$
\mathrm{RPN}=\mathrm{P} \times \mathrm{S} \times \mathrm{D} .
$$

where $\mathrm{P}$ - the probability of a defect, S - the severity of its manifestation, and D - the detectability when checked, each in the range from 1 to 10 .

Having analyzed in detail the shortcomings of previous attempts to combine FMECA with fuzzy methods, the authors introduce additional weights of probability, severity, and detectability into formula (2). The weight distributions are found using fuzzy methods based on an expert survey. The final risk assessment is performed on a $3 \times 3$ matrix. The results of testing the method at the Taiwan airport are presented. But it seems that the resulting risk assessment matrix may be too rough for the risks of aviation activities, and the applicability of the method to other types of aviation organizations (for example, for airlines) will require additional verification.дД

When developing an Automated System for Predicting and Preventing Accidents (ASPPA) at Volga-Dnepr Airlines [18, 19], expert evaluation was widely used, including elements of the FST. For example, to assess the impact of a pilot's age on the risk of an upcoming flight, we used our own estimates together with data from well-known studies. Fig. 1 shows the results of processing expert assessments, the experts were experienced pilots of the airline. Linguistic variable (LV) is "Risk assotiatrd with pilot's age".

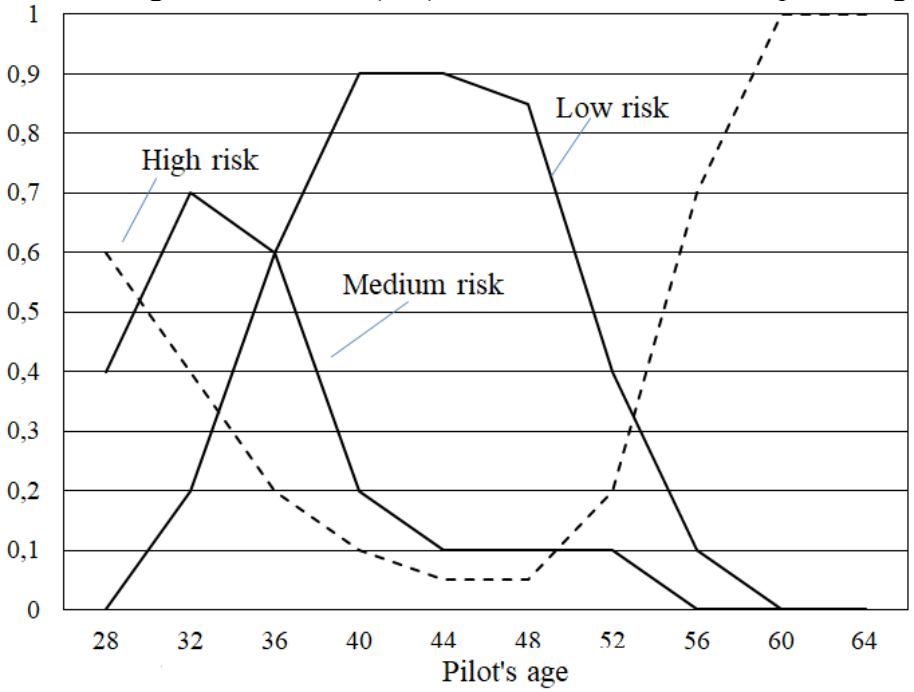

Fig. 1 Membership function for the LP "Risk associated with pilot's age" 


\section{Assessment of oconditional coefficients for severity and probability}

The task for developing Automated System for Risk Management (ASRM) in the S-7 airline was set as follows. Taking into account information about events and shortcomings in operations quantify the risks in the reporting period. Safety manager should concider this risk as a forecast for next period and develop, if nessery, risk mitigation measures.

As experience shows, if in airline with 60 aircraft all the inconsistencies (from minor to incidents) are recorded, then there will be more than 1 thousand facts per month. For structuring information a classifier has been developed with more than 100 categories. Each $\mathrm{i}$-th fixed shortcoming or event found itself in one of the $\mathrm{j}$-th category.

The risk is calculated to each $\mathrm{j}$-th category by formula (1).

Expert valuates event severity index Ki of each event. Then it is translfotmed into the severity level coefficient Sij according to Table 2, based on SAFA (Safety Assessment of Foreign Aircraft, EU program) approach.

Table 2. Converting the event severity to the severity level

\begin{tabular}{|c|c|c|c|c|c|}
\hline $\mathrm{Ki}$ & 1 & 2 & 3 & 4 & 5 \\
\hline $\mathrm{Sij}$ & 1 & 4 & 8 & 16 & 32 \\
\hline
\end{tabular}

To calculate the cumulative severity of $S_{j}^{*}$ in a category over a period, it is assumed that each value of $S_{i}$ is a realization of a random variable $S$, and $S_{\mathrm{j}}^{*}$ is the upper bound of the confidence interval for $\mathrm{P}=0.75$, defined by Bienaymé-Chebyshev inequality as:

$$
\mathrm{S}_{\mathrm{j}}^{*}=\mathrm{M}(\mathrm{S})+2 \sigma(\mathrm{S})
$$

where $M S$ и $\sigma(S)$ - mathematical expectation and standart deviation of S.

But if sum $\mathrm{M}\left(\mathrm{S}_{\mathrm{j}}\right)+2 \sigma\left(\mathrm{S}_{\mathrm{j}}\right)$ exceeds the largest value of the observed values. Sij $\left(\mathrm{S}_{\mathrm{j}}^{\max }\right)$, is accepted that $S j^{*}=\operatorname{Sjmax}$.

Thus, the rule for calculating the total risk of the category is adopted as:

$$
\left\{\begin{array}{ll}
S_{j}^{*}=M\left(S_{j}\right)+2 \sigma\left(S_{j}\right) & \text { при } M\left(S_{j}\right)+2 \sigma\left(S_{j}\right) \leq S_{j}^{\max } \\
S_{j}^{*}=S_{j}^{\max } & \text { при } M\left(S_{j}\right)+2 \sigma\left(S_{j}\right)>S_{j}^{\max }
\end{array}\right\} .
$$

Value of the probability index $\mathrm{P}^{*}$ for each category is based on the frequency of $F j$, which is calculated as:

$$
F_{j}=\frac{N_{j}}{n} 1000,
$$

where $\mathrm{N}_{\mathrm{j}-\text { number }}$ of events and deficiencies in the category for a certain period, $\mathrm{n}$ - number of flights.

The function $P^{*}=f(F)$ is formed using FST. Here the linguistic variable (LV) is called "Frequency", its five terms are "Very Often", "Often", "Sometimes", "Rare", "Extremely Rare".

The Sugeno-type fuzzy inference is used with MATLAB Fuzzy Logic Toolbox package [20]. The scheme is shown in Fig. 2. 


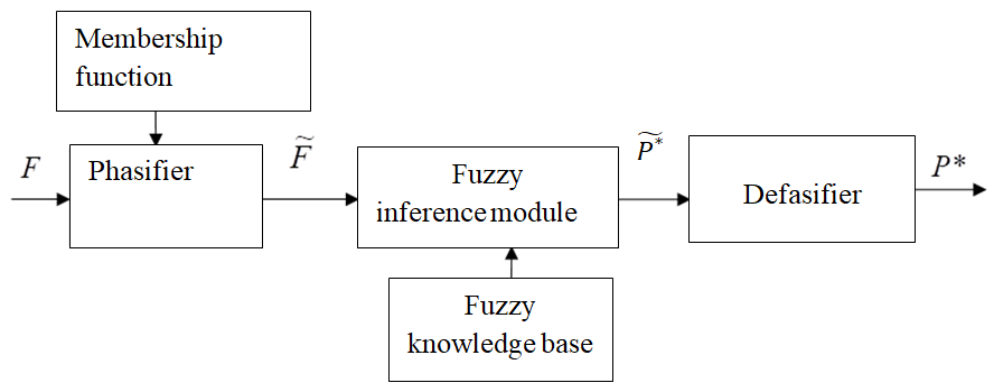

Fig. 2 Fuzzy inference system for $\mathrm{P}^{*}$

To solve the problem, it is necessary to:

(a) construct the membership functions (MF) of fuzzy terms of the LP "Frequency";

(b) develop a system of rules for building a knowledge base;

(c) get the output values of $\mathrm{P}^{*}$ by setting the input values of $\mathrm{F}$.

The MF of these terms are based on the expert survey method. Each of $\mathrm{N}$ experts involved fills out a questionnaire (Fig. 3), where he indicates his opinion on whether or not an element belongs to a fuzzy set: 1 - the element belongs to the set, 0 - does not.

\begin{tabular}{|c|c|c|c|c|c|c|c|c|c|c|}
\hline \multicolumn{2}{|c|}{$\begin{array}{r}\text { Number of events per } \\
1000 \text { flights }\end{array}$} & 0,2 & 0,6 & 1,0 & 1,5 & 1,9 & 2,3 & 2,7 & 3,1 & 3,5 \\
\hline \multirow{5}{*}{ 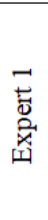 } & Extremely rare & 1 & & & & & & & & \\
\hline & Rare & & 1 & & & & & & & \\
\hline & Sometimes & & & 1 & 1 & 1 & 1 & 1 & 1 & 1 \\
\hline & Often & & & & & & & & & \\
\hline & Very often & & & & & & & & & \\
\hline \multirow{5}{*}{ 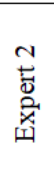 } & Extremely rare & 1 & & & & & & & & \\
\hline & Rare & & 1 & 1 & & & & & & \\
\hline & Sometimes & & & & 1 & 1 & 1 & 1 & & \\
\hline & Often & & & & & & & & 1 & 1 \\
\hline & Very often & & & & & & & & & \\
\hline
\end{tabular}

Fig. 3 Fragment of the expert survey questionnaire

The degree of belonging of the $\mathrm{u}_{\mathrm{i}}$ element to the fuzzy set $\mathrm{Aj}$ is calculated as:

$$
\mu_{A j}\left(u_{i}\right)=\frac{1}{N} \sum_{k=1}^{N} c_{j, i}^{k}
$$

where $c_{i, j}^{k}$ - the opinion of the $\mathrm{k}$-th expert on whether the $\mathrm{i}$-th element (interval) belongs to the j-th fuzzy set.

The diagfam of the raw MF based on formula (6), is shown in Fig. 4. 


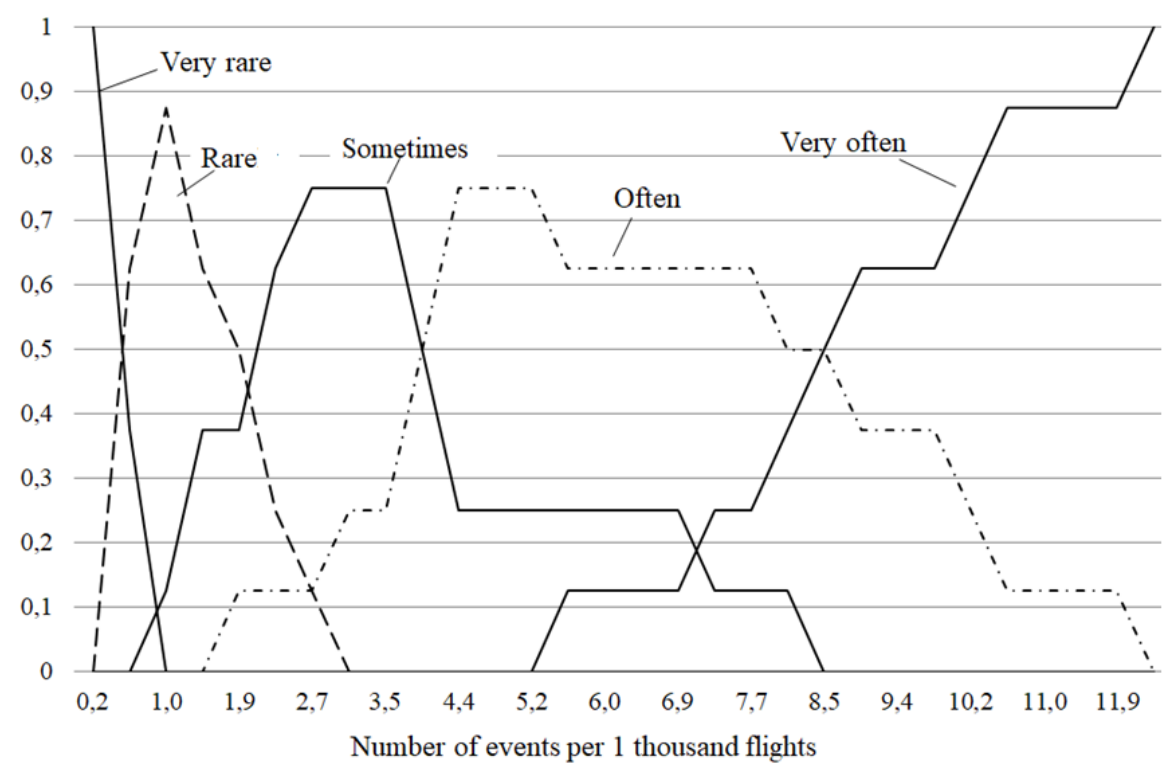

Fig. 4 Raw membership functions (subnormal fuzzy sets)

The normalization of the MF is carried out according to the formula from [16]

$$
\widetilde{A}=\operatorname{norm}(\widetilde{A}) \Leftrightarrow \mu_{A}(u)=\frac{\mu_{A}(u)}{\operatorname{hight}(\widetilde{A})},
$$

where $\operatorname{hight}(\tilde{A})-$ maximum of MF.

The MF terms of the LV "Frequency" were approximated by triangular and trapezoidal functions, there parameters presented in table 3 . MF in parametric form are presenteg on Fig. 5.

Table 3 Types and parameters of membership functions

\begin{tabular}{|c|c|c|}
\hline Name of MF & Type & Parameters \\
\hline Extremely rare & Trapezoidal & $\mathrm{a}=0 ; \mathrm{b}=0 ; \mathrm{c}=0,21 ; \mathrm{d}=1$ \\
\hline Rare & Triangular & $\mathrm{a}=0,21 ; \mathrm{b}=1,04 ; \mathrm{c}=3,13$ \\
\hline Sometimes & Trapezoidal & $\mathrm{a}=0,63 ; \mathrm{b}=1,71 ; \mathrm{c}=3,54 ; \mathrm{d}=8,54$ \\
\hline Often & Trapezoidal & $\mathrm{a}=1,46 ; \mathrm{b}=4,38 ; \mathrm{c}=5,21 ; \mathrm{d}=12,29$ \\
\hline Very often & Trapezoidal & $\mathrm{a}=5,21 ; \mathrm{b}=12,29 ; \mathrm{c}=15 ; \mathrm{d}=15$ \\
\hline
\end{tabular}

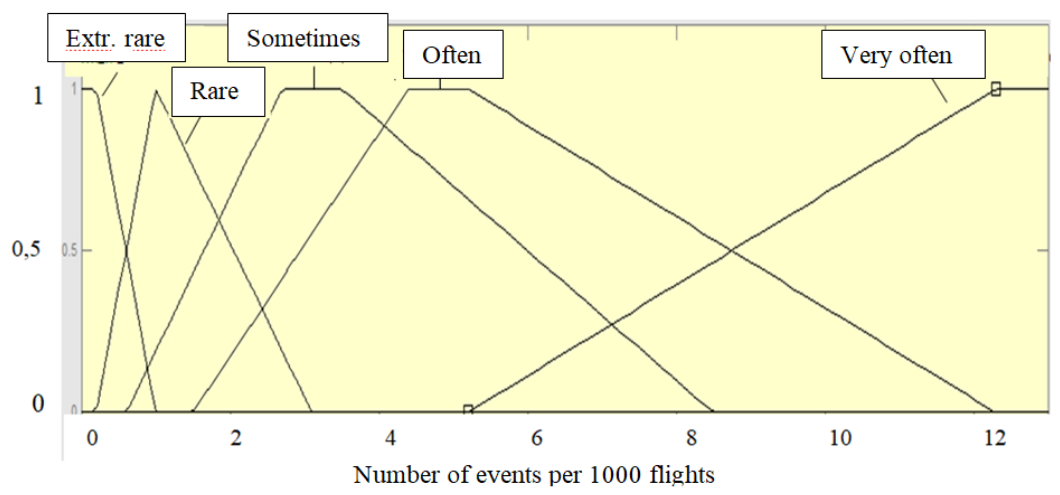

Fig. 5 Membership functions in parametric form at the MATLAB input 
The knowledge base consists of five simple rules from the ICAO matrix: if the frequency is "extremely rare", then the indicator $P^{*}$ is 1 , if the frequency is "rare", then the indicator -2 , and so on.

The calculation of $\mathrm{P}^{*}$ in the Sugeno system is performed by simply setting the input frequency value in the corresponding program window. The output variable $\mathrm{P}^{*}$ is a clear number. Figure 6 shows the final view of the dependence $P^{*}$ of $F$.

The dependence is approximated by the function $P^{*}=1,695 \ln F+0,597$, which was used in the software of ASRM developed in S-7 airline.

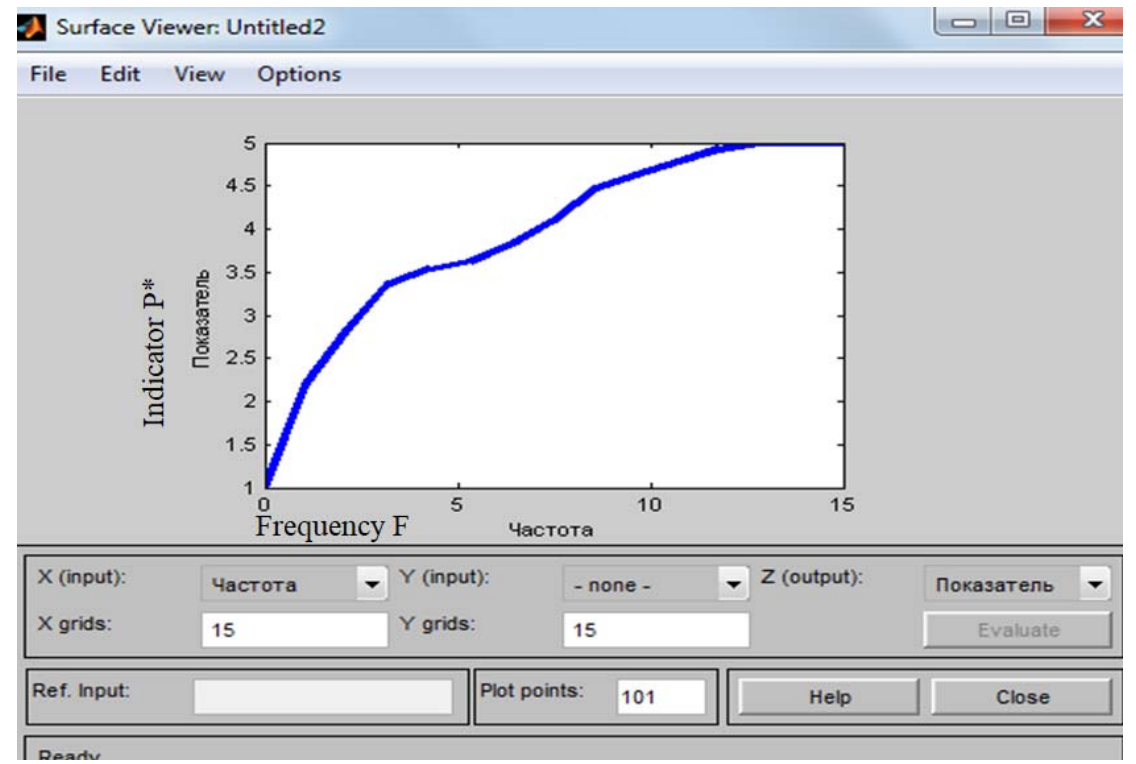

Fig. 6 Function $P^{*}=f(F)$ based on Sugeno fuzzy inference in MATLAB

\section{Results and discussion}

The conducted analysis has shown that the FST methods are increasingly used in the risk management systems of airlines. The most promising is the integrated use of FST and modern risk management methods of socio-technical systems.

The proposed method is applicable for risk assessment if the airline has a wellestablished system for collecting information about nonconformities that are considered as manifestations of hidden hazards. Risk assessment by categories (aspects of activity) of the airline helps to identify dynamics of risks and take preventive measures.

Methodology for evaluating the conditional indicator of the probability of an event $\mathrm{P} *$ uses the fuzzy inference technology in the MATLAB environment. The assessment is based on an expert survey and reflects as objectively as possible the understanding of the linguistic concepts "often", "sometimes", etc. in this organization.

Obviously, expert surveys should be repeated periodically to update the $P^{*}=f(F)$ function in accordance with the changing priorities of management, employees of the organization, as well as changing regulatory requirements.

Conclusion: the results obtained can be used in automated risk management systems to improve the efficiency of airline SMS.

Acknowledgments: The reported study was funded by RFBR, project number 19-38-90215. 


\section{References}

1. Decree of the Government of the Russian Federation No. 1215 of 18.11.2014. (2014).

2. Annex 19 to the Convention on international civil aviation. Safety management, ICAO, 2-d ed, (2016).

3. Safety Management Manual (SMM), Doc.9859,ICAO, 4-th ed. (2018).

4. N.A. Mahutov, K.B. Pulikovskij, S.K. Shojgu Security of Russia. Legal, socioeconomic, scientific and technical aspects. Risk analysis and security management, M.: "Znanie", (2008).

5. Cox L. What's Wrong with Risk Matrices?, Risk Analyses. V. 28, № 2. 8. - pp. 497-512. (2008).

6. N.A. Mahutov, D.O. Reznikov, V.P. Petrov, V.I. Kukseva Use of risk matrices in risk assessment and prioritization of protective measures, Security and emergency issues. 2012. - No. 1. - p. 82-92. (2012).

7. V.D. Sharov, V.V. Vorobyov, D.A. Zatuchny. Risk Management Methods in the Aviation Enterprise. Springer Link, - 146 p. (2021).

8. CAP-712 Safety Management Systems for Commercial Air Transport Operation, Appendix 1. UK CAA, (2002).

9. L.A Zadeh. Fuzzy logic-A personal perspective. Fuzzy Sets Syst, 281, 4-20. (2015)

10. B.K. Boss Expert system, fuzzy logic, and neural network applications in power electronics and motion control Proceedings of the IEEE V. 82, Issue: 8, pp 1303 - 1323 (1994)

11. H. Slim, S. Nadeau. A Proposition for Combining Rough Sets, Fuzzy Logic and FRAM to Address Methodological Challenges in Safety Management: A Discussion Paper. Safety, 6 (4), 50; (2020)

12. M. Hadjimichael. A fuzzy expert system for aviation risk assessment. Expert Systems with Applications, V. 36, no. 3, pp. 6512-6519, (2009).

13. E, Kuklev, V. Zhilinsky. Accident risk assessment for highly reliable aviation systems in emergency situations, Transport and Telecommunication, v. 19, no. 1, pp. 59-63. (2018).

14. A. Shcherban, V. Ieremenko. UAV Flight Safety System Based on Fuzzy Logic. Transaction on Aerospace Research (4): pp. 71-80. (2020)

15. K. Jenab1, J. Pineau. Automation of Air Traffic Management Using Fuzzy Logic Algorithm to Integrate Unmanned Aerial Systems into the National Airspace. International Journal of Electrical and Computer Engineering (IJECE) V. 8, No. 5, pp. 3169 3178 (2018)

16. R.V. Enikeev. Methods of flight safety management in aircraft maintenance organizations. Dissert. Cand. of Tech. Sciences, Moscow (2016).

17. C. M. Feng. C. C. Chung. Assessing the Risks of Airport Airside through the Fuzzy Logic-Based Failure Modes, Effect, and Criticality Analysis. Mathematical Problems in Engineering. V. 2013 Article ID 239523 (2013)

18. A.A. Butov, M.A. Volkov, V.D. Sharov Principles of developing a system for predicting and preventing accidents in the organization and production of air transportation. Proceedings of the Samara Scientific Center of the Russian Academy of Sciences. V. 14 No. 4(2), pp. 386-393. (2012)

19. A.I. Orlov, Yu.G. Savinov, A.Yu. Bogdanov. Experience in expert evaluation of conditional probabilities of rare events in the development of an automated system for predicting and preventing accidents. Proceedings of the Samara Scientific Center of the Russian Academy of Sciences. V.14 No. 4(2), , pp. 501-506. (2012).

20. S.D. Shtovba. Designing fuzzy systems by means of MATLAB.- M.: Hotline-Telecom.288 p. (2007). 